\title{
Treatment seeking behavior of filariasis patients in a selected endemic area of Bangladesh
}

\author{
KMM Rahman ${ }^{1}$, MS Laskar², BK Basu ${ }^{3}$, S Chowdhury ${ }^{4}$
}

\begin{abstract}
This descriptive cross-sectional study was carried out among 400 respondents from the rural area in Parbatipur Upazilla under Dinajpur district with the objectives to assess the knowledge, attitude, practice and gender discrimination of filariasis patients using a semi structured questionnaire through face to face interview. After collection of data, they were checked, verified, edited for consistency and entered into a computer. The statistical calculation and analysis were done to fulfill the objectives of the study. All the respondents were adult, age ranged from 20 to 71 years; mean (SD) was 41.3 (11.6). Among them $59.0 \%$ were female and $41.0 \%$ were male, about $90.5 \%$ were married, $68.5 \%$ were illiterate and $4.0 \%$ had higher secondary education. About $78.5 \%$ of the respondents in the studied area had no knowledge about the disease. All the respondents had incorrect concept about the causes of the disease. About $85 \%$ of the respondents mentioned that the symptoms of the disease was swelling of the hand and feet, $12.6 \%$ reported no specific symptoms or had no knowledge on symptoms of the disease; $67.8 \%$ of the men reported swelling of the scrotum. About $94 \%$ of the respondents did not know the easiest method of prevention. About $73.8 \%$ of the respondents delayed in receiving the treatment and $26.3 \%$ received treatment immediately after appeared of symptoms. About $51.5 \%$ respondents did not take the disease seriously and $48.5 \%$ did not receive advice from any one. From the respondents, $89.5 \%$ received treatment from homeopaths, $83.5 \%$ from kabiraj, and $7.8 \%$ from doctors with MBBS (from private clinics) and $0.3 \%$ from government hospitals. Analysis revealed that female respondents received different pattern of treatment than male counterpart. Active community participation should be ensured in designing community based education campaigns to make them socially acceptable and effective. Health workers, NGO workers, teachers, religious leaders, community leaders can play a key role convincing the patients to take modern treatment and enhancing the intake of full course of drugs against filariasis by the patients. Further study is needed using a large scale patients to observe the actual status of treatment seeking behavior of filariasis patients in the community.
\end{abstract}

Key words: Treatment seeking behavior, filariasis patients, Bangladesh.

1. KMM Rahman MD, MPH, Applied Research \& Innovation Center, Centennial College, 941 Progress Ave., Room: D2-04, Toronto ON Canada M1G 3T8. Email: rinkirafi@yahoo.com

2. MS Laskar MD, MPH, PhD, Professor of Community Medicine, Gazi Medical College, Khulna-9100, Bangladesh. Tel: +88-01714208781; Email: laskarms@gmail.com

3. BK Basu MD, PhD, Associate Professor, Department of Surgery, Gazi Medical College, Khulna, Bangladesh. Tel: +88-01712744736; Email: bangakamalb@yahoo.com

4. S Chowdhury MA, Assistant Professor, Department of English, Government Mazid Memorial City College, Khulna 


\section{Introduction}

Lymphatic filariasis (LF) is a mosquito-borne tropical disease, which afflicts around 120 million people worldwide. The World Health Organization (WHO) ranks it as the second common cause of long term disability. ${ }^{1}$ LF is a major public health problem and inflicts a considerable social and economic burden on many tropical and sub-tropical countries. Vector-borne disease control programs mostly rely on controlling the parasite and/or vector and have often overlooked the importance of the target population's knowledge, beliefs and behavior in the transmission and control of disease. ${ }^{2}$

It is estimated that there are about 700 million people living in the endemic areas in South-East Asia Region constituting about $64 \%$ of the global burden with about 60 million persons either harboring microfilaraemia or suffering from clinical manifestations which constitute about half of the global figure. All the three lymphatic filarial parasites viz. W. bancrofti, B. malayi and $\mathrm{B}$. timori are prevalent in the region. Bancroftian filariasis transmitted by the ubiquitous principal vector, Culex quinquefasciatus, is the most predominant infection in the continental Asia while Brugian infections transmitted by Mansonia and Anopheles vectors predominate in Indonesian Archipelago. ${ }^{3}$ The nine known endemic countries in the region are: Bangladesh, India, Indonesia, Maldives, Myanmar, Nepal, Sri Lanka, Thailand and Timor-Leste. LF control programs are in operation in all endemic countries, having national goals to achieve elimination by $2020 .{ }^{4}$

In $4000 \mathrm{BC}$ LF is one of the oldest and most debilitating diseases in the world. Centuries-old art and texts from Egypt, Japan, Africa, Persia and India depict the disease. In the Egyptian Museum in Cairo there is a 4000 years-old statue of a Pharaoh Depicting possible signs of elephantiasis. It is an ancient scourge that remains as second leading cause of permanent and long-term disability. ${ }^{5}$ All cases of elephantiasis are not caused by filariasis and elephantiasis is not the most common symptom of LF; however, it is the most visible and has been known since early times. Elephantiasis features in the mythology of several societies. Tales of 'Skiapodes' mythical beings who could 'shade themselves from the sun by the greatness of their legs' occur in the mythology of Greece, Italy and India. Indian mythology also contains the legend of the 'curse of St. Thomas' which states that swollen legs occur in the descendants of those who martyred him. ${ }^{1}$

In 1947 following the introduction of the drug Diethylcarbamazine (DEC) for the treatment of the disease, a number of countries (Japan, China, Malaysia, Korea, some islands in the Pacific) made significant progress in control of $\mathrm{LF}^{5}$ In 1993, an independent International Task Force for Disease Eradication identified LF one of the six eliminable infectious diseases. LF was selected because of advances in treatment methods, both for controlling transmission and for managing the disease. There had also been remarkable improvement in techniques for diagnosing filarial infections. ${ }^{5}$

In 1997 the World Health Assembly adopted a resolution calling for the elimination of LF as a public health problem worldwide. The principal strategy for interrupting transmission of infection is to identify areas in which LF is endemic and then implement community-wide programmes to treat the entire at-risk population to break the cycle of transmission between mosquitoes and humans by annual co-administration of one of the anti-filarial drugs- Ivermectin or DEC with Albendazole. ${ }^{5}$

In 1998, WHO and GlaxoSmithKline (GSK) announced a worldwide collaboration to fight against LF. This collaboration has now become a global alliance of 40 private and public institutions along with LF endemic countries, through their Ministries of Health, all committed to fighting LF. GSK announces its commitment to donate sufficient quantities of its anti-parasitic medicine, Albendazole, for use in all LF endemic countries for as long as it takes to eliminate the disease. ${ }^{5}$ 
In 2000, three million people were protected from LF through the distribution of Albendazole plus either Mectizan or DEC in 12 countries. ${ }^{5}$ In 2001, twenty six million people were protected through the distribution of LF preventive medicines in 22 countries. ${ }^{5}$ In 2002, sixty million people in 32 countries received the treatment. At least 8 countries started programs to reduce suffering and disability of those affected by the disease. ${ }^{5}$ In 2004, globally 980 million people received Mass Drug Administration (MDA). In South East Asian Region (SEAR), 636 million people are at risk and 64 million of them received MDA (DEC+ Albendazole). In addition India covered 360 million by DEC alone. ${ }^{5}$

Bangladesh is known to be surrounded by endemic area of filariasis particularly the north-east border area adjacent to the Assam, Bihar, and West Bengal of India. The northern districts of Bangladesh especially greater Dinajpur and Rangpur are surrounded by the hyper endemic filarial zone of India, therefore, the prevalence rate of filariasis are higher in these two areas than the rest of the country. The affected patients are burden to the family, society, and economy. Poverty, malnutrition, superstition, illiteracy, unhygienic condition of the dwelling house, overcrowding, etc are responsible aggravating factors for the disease. LF is a so-called neglected tropical disease, currently overshadowed by higher-profile efforts to address malaria, tuberculosis, and HIV/AIDS. Despite recent successes in arresting transmission, some 40 million people who already have the disease have been largely neglected. Recently, the profile of the 'neglected diseases' has been enhanced by a renewed interest by policymakers, including the new Director-General of WHO. These diseases cause long-term morbidity, rather than high mortality, but have been overshadowed by higher-profile efforts to address malaria, tuberculosis, and HIV/AIDS. ${ }^{6}$ Recent studies show extensive and underestimated morbidity for the neglected diseases, totaling around 56 million cumulative disabilityadjusted life years, which is more than for malaria and tuberculosis. ${ }^{7,8}$ LF is one of these diseases and one of the leading causes of disability, infecting some 120 million individuals, with a further 1.3 billion people at risk. ${ }^{9}$ It was reported that 120 million people in over 80 countries have LF, 44 million have recurrent infections and abnormalities of renal function, another 76 million have pre-clinical, internal damage to their lymphatic and renal systems. ${ }^{10,11}$ One fifth of the world's population is at risk of infection from LF. The 1998 World Health Report ranked LF fourth in global causes of serious disability. ${ }^{12}$

The consequences of filarial infection are many. A large number of afflicted persons exhibit physical and mental disabilities, an impaired ability to work, and a compromised quality of life. These problems arise not only from the disease process, but also from social stigma directed toward the afflicted persons. All of these problems, moreover, have a cumulative, adverse effect at the individual, household, community and national level. Misconceptions and ignorance could adversely affect personal protection measures against mosquito bites and the use of appropriate treatment. Health education campaigns aimed at highlighting the role of mosquitoes in transmission and the importance of early diagnosis should help people in taking personal protection measures and seeking appropriate treatment. The impact of human behavioural and socio-economic factors pertinent to the control of filariasis has been largely ignored and there have been few attempts to bridge the gap between modern medical knowledge about filariasis and indigenous perception of the disease. A variety of factors have been identified as the leading causes of poor utilization of primary health care services: including poor socio-economic status, lack of physical accessibility, cultural beliefs and perceptions, low literacy level of the mothers and large family size. Review of the global literature suggests that these factors can be classified as cultural beliefs, sociodemographic status, women's autonomy, economic conditions, physical and financial accessibility, and disease pattern and health service issues. 
To develop rational policy to provide efficient, effective, acceptable, cost-effective, affordable and accessible services, we need to understand the drivers of health seeking behavior of the population in an increasingly pluralistic health care system. This relates both to public as well as private sectors. LF has been identified as a potentially eradicable disease and the 50th World Health Assembly 1997 passed a resolution that elimination of LF as a public health problem should be considered a priority by member states. Delimitation of endemic localities is an essential prerequisite for planning control or elimination programmes. The Bangladesh Ministry of Health and Family welfare initiated the LF elimination programme in 2001 with assistance from AUSAID, WHO and others.

The aims of this study is to explore specific health beliefs, health seeking behavior and gender discrimination with LF patients in filariasis endemic areas of Bangladesh about which little is known and to provide recommendation for morbidity control programmes for LF management.

\section{Materials and Method}

LF is a major public health problem and inflicts a considerable social and economic burden on many tropical and sub-tropical countries. Vector-borne disease control programmes mostly rely on controlling the parasite and/or vector and have often overlooked the importance of the target population's knowledge, beliefs and behavior in the transmission and control of disease.

\section{Study design}

It was descriptive cross-sectional study and was designed with a view to assess the knowledge and perception of the people with filariasis about the disease and also to identify the care seeking behavior of the people.

\section{Place of study}

This was conducted in four selected village of Palashbari union under Parbatipur upazilla, Dinajpur. Distance from Dhaka to
Dinajpur is $430 \mathrm{~km}$. The study areas were selected purposively.

\section{Study population and study period}

All the currently suffering from LF patients aged 15 years and above irrespective of gender in selected villages. The whole study was conducted in a period of six months started during January to June, 2008.

\section{Sample selection and sample size}

The endemic district of filariasis was selected purposively. From the selected district, four villages were selected randomly then each and every household was visited and inquired for filariasis. From the infected house, one respondent was selected for interview and the number of patients successfully interviewed was 400 .

\section{Survey instruments}

A semi-structured interview schedule was developed keeping the objectives and variables to be studied in mind. The questionnaire contained five parts consisting of personal and socio-demographic information, information about the diseases and socio-cultural barrier, environmental information, information about the treatment, and information about gender discrimination.

\section{Conduction of the study, quality control and monitoring}

The collected data were checked and verified by the authors at the end of work in each day. Any inaccuracy and inconsistency was corrected in the next working day. Cross-checking of the collected data was made randomly.

\section{Data processing and analysis}

After data input into a computer, the data were again checked, verified and corrected for consistency. By using SPSS software (Statistical Package for Social Science) data were analyzed to fulfill the objectives of the study.

\section{Results}

Table 1 shows the age distribution of the respondents, the mean (SD) was 41.3 
Table 1. Distribution of the respondents by age

\begin{tabular}{lcc}
\hline Age in years & Frequency & $\%$ \\
\hline$<30$ & 79 & 19.8 \\
$30-39$ & 120 & 30.0 \\
$40-49$ & 124 & 31.0 \\
$50-59$ & 37 & 9.3 \\
$>60$ & 40 & 10.0 \\
\hline Total & 400 & 100.0 \\
\hline
\end{tabular}

Table 2. Distribution of the respondents by knowledge about the disease they are suffering from

\begin{tabular}{lcc}
\hline Knowledge about the disease & Frequency & $\%$ \\
\hline Yes & 79 & 21.5 \\
No & 120 & 78.5 \\
\hline Total & 400 & 100.0 \\
\hline
\end{tabular}

Table 3. Distribution of the respondents by knowledge about symptoms of the disease

\begin{tabular}{lcc}
\hline Symptoms of the disease & Frequency & $\%$ \\
\hline Swelling of hand and feet & 340 & 85.0 \\
Swelling of scrotum & 271 & 67.8 \\
Non specific & 21 & 5.3 \\
Do not know & 29 & 7.3 \\
\hline Total & 400 & 100.0 \\
\hline
\end{tabular}

Table 4. Distribution of the respondents by knowledge of easiest methods of prevention

\begin{tabular}{lcc}
\hline Easiest methods of prevention & Frequency & $\%$ \\
\hline $\begin{array}{l}\text { Destruction of mosquito, fly, } \\
\text { cleanliness and use of curtain }\end{array}$ & 24 & 6.0 \\
Do not know & 376 & 94.0 \\
\hline Total & 400 & 100.0 \\
\hline
\end{tabular}

$( \pm 11.6)$ ranging from 20 to 71 years. Highest percentages were in the age group 40-49 years $124(31.0 \%)$ followed by $30-39$ years $120(30.0 \%)$, less than 30 years $79(19.8 \%)$, 60 years and above $40(10.0 \%)$ and lowest in the age group $50-59$ years 37 (9.3\%).

Out of 400 respondents, 236 (59.0\%) were female and the rest were male 164 (41.0\%) with male and female ratio was $0.69: 1$; $90.5 \%$ were married, 274 (68.5\%) were illiterate followed by $88(22.0 \%)$ had primary level of education, 22 (5.5\%) secondary education and $16(4.0 \%)$ higher secondary. Majority of the respondents were Muslim $362(90.5 \%)$ and $38(9.5 \%)$ were non- 
Table 5. Distribution of the respondents by time of starting treatment and delayed treatment

\begin{tabular}{lcc}
\hline Time of starting treatment & Frequency & $\%$ \\
\hline Immediately after appearance of symptoms & 105 & 26.2 \\
Delay in receiving treatment & 295 & 73.8 \\
\hline Total & 400 & 100.0 \\
\hline Reasons for delayed treatment & & \\
Do not take seriously & 152 & 51.5 \\
No advice & 143 & 48.5 \\
\hline Total & 295 & 100.0 \\
\hline
\end{tabular}

Table 6. Distribution of the respondents by usual place of treatment; $(n=400)$

\begin{tabular}{lcc}
\hline Usual place of treatment & Frequency & $\%$ \\
\hline Doctor's chamber (Homeopath) & 358 & 89.5 \\
Kabiraj & 334 & 83.5 \\
Pvt. Clinic (MBBS) & 31 & 7.8 \\
Govt. hospital & 1 & 0.3 \\
\hline
\end{tabular}

Note: the value (\%) is not rounded to $100 \%$ as there were multiple responses.

Table 7. Distribution of the respondents by some selected variables; $(n=400)$

\begin{tabular}{lcc}
\hline Usual place of treatment & Frequency & $\%$ \\
\hline Purchase of medicine in right time & 273 & 68.3 \\
Investigation was done timely & 203 & 50.8 \\
Doctor listened the complaints attentively & 180 & 45.0 \\
Treatment given attentively & 179 & 44.8 \\
Treatment received in right time & 169 & 42.3 \\
\hline
\end{tabular}

Muslim. Half of the respondents were housewives $206(51.5 \%)$ followed by 67 $(16.8 \%)$ were engaged in agriculture farming, $38(9.5 \%)$ were van driver, day laborers $27(9.3 \%)$, service holder 20 (5.0\%), business $19(4.8 \%)$ and $13(3.3 \%)$ were unemployed.

The mean family size of the respondents was $4.91 \pm 1.2$ ranging from 2 to 8 . Highest percentage of the respondents had 5 family members $129(32.3 \%)$ followed by 4 members 118 (29.5\%), 113 (28.3\%) had family members 6 and above and 40 $(10.0 \%)$ had 2 to 3 members.
The mean monthly family income was Taka $3792.8 \pm 1099.3$ ranging from 2000 to 8000 . Highest percentage of the respondents had monthly income up to 3000,143 (35.8\%); followed by 3001-4000, 142 (35.5\%); 4001-5000, $84(20.8 \%)$ and $32(8.0 \%)$ had monthly income in the range of Taka 5001 and above.

Majority of the respondents living in katcha house $352(88.0 \%)$ and only 48 (12.0\%) living in tin shed house. Majority of the household were surrounded by bush 267 $(66.8 \%)$ followed by dirty drain $213(53.3 \%)$, dirty ditch 198 (49.5\%). However, 68 $(17.0 \%)$ of the household were clean. 
Table 8. Distribution of the respondents by gender discrimination in treatment

\begin{tabular}{|c|c|c|c|c|c|c|c|}
\hline \multirow[t]{3}{*}{ Variables } & \multicolumn{4}{|c|}{ Sex } & \multirow{2}{*}{\multicolumn{2}{|c|}{$\begin{array}{c}\text { Total } \\
(\mathrm{n}=400)\end{array}$}} & \multirow{3}{*}{$\begin{array}{r}p \\
\text { value }\end{array}$} \\
\hline & \multicolumn{2}{|c|}{$\begin{array}{c}\text { Male } \\
(n=164)\end{array}$} & \multicolumn{2}{|c|}{$\begin{array}{l}\text { Female } \\
(n=236)\end{array}$} & & & \\
\hline & No. & $\%$ & No. & $\%$ & No. & $\%$ & \\
\hline \multicolumn{8}{|c|}{ Treatment received in right time } \\
\hline Yes & 89 & 54.3 & 80 & 33.9 & 169 & 42.3 & 0.001 \\
\hline No & 75 & 45.7 & 156 & 66.1 & 231 & 57.8 & \\
\hline \multicolumn{8}{|c|}{ Investigation was done timely } \\
\hline Yes & 120 & 73.2 & 83 & 35.2 & 203 & 50.8 & 0.001 \\
\hline No & 44 & 26.8 & 153 & 64.8 & 197 & 49.3 & \\
\hline \multicolumn{8}{|c|}{ Purchase of medicine in right time } \\
\hline Yes & 127 & 77.4 & 146 & 61.9 & 273 & 68.3 & 0.001 \\
\hline No & 37 & 22.6 & 90 & 38.1 & 127 & 31.8 & \\
\hline \multicolumn{8}{|c|}{ Doctor listened the complaints attentively } \\
\hline Yes & 91 & 55.5 & 89 & 37.7 & 180 & 45.0 & 0.001 \\
\hline No & 73 & 44.5 & 147 & 62.3 & 220 & 55.0 & \\
\hline \multicolumn{8}{|c|}{ Treatment given attentively } \\
\hline Yes & 91 & 55.5 & 88 & 37.3 & 179 & 44.8 & 0.001 \\
\hline No & 73 & 44.5 & 148 & 62.7 & 221 & 55.3 & \\
\hline
\end{tabular}

$p$ value received by chi-square test

About $78.5 \%$ of the respondents in the studied area had no knowledge about the disease (Table 2). All the respondents had incorrect concept about the causes of the disease. About $85 \%$ of the respondents mentioned that the symptoms of the disease was swelling of the hand and feet, $12.6 \%$ reported no specific symptoms or had no knowledge on symptoms of the disease; $67.8 \%$ of the men reported swelling of the scrotum (Table 3 ).

Considering the easiest method of prevention of disease, majority of the respondents had no knowledge on prevention of disease and 24 (6.0\%) reportedly mentioned that destruction of mosquito, fly, cleanliness and use to curtain could prevent the disease (Table 4).

It was found that majority of the respondents delay in receiving the treatment 295 (73.8) and only $105(26.3 \%)$ received treatment immediately after appearance of symptoms (Table 5). The main reasons for delay in treatment was that they did not take the disease as serious one $152(51.5 \%)$ and 143
$(48.5 \%)$ had reportedly mentioned that they did not receive advice from any one.

Regarding the usual place of treatment, majority of the respondents visited to the Homeopath Doctor's chamber 358 (89.5\%) followed by Kabiraj 334 (83.5\%), Pvt. Clinic (MBBS) $31(7.8 \%)$ and one respondent mentioned that the usual place of treatment was government hospital (Table 6).

Considering the treatment related variables, $273(68.3 \%)$ respondents reportedly mentioned that they received medicine right time followed by 203 (50.8\%) mentioned that the investigation was done timely, doctor listen their complaints attentively 180 $(45.0 \%)$, treatment given attentively 179 $(44.8 \%)$ and 169 (42.3\%) reportedly mentioned that treatment received in right time (Table 7).

A bivariate analysis was done to assess the gender discrimination of treatment of filariasis (Table 8). Analysis revealed that the female respondents were received different sorts of treatment than male counterpart. 
That is in terms of treatment received in right time $(54.3 \%$ vs $33.9 \%)$, investigation $(73.2 \%$ vs $35.2 \%)$, purchase of medicine $(77.4 \%$ vs $61.9 \%)$, doctor listened the complaints (55.5\% vs $37.7 \%)$ and attentive treatment $(55.5 \%$ vs $37.3 \%)$. This indicates that female respondents had been discriminated for the treatment of filariasis.

\section{Discussion}

Filariasis is still the most important public health parasitic disease in Bangladesh. The consequences of filarial infection are many. A large number of affected persons exhibit physical and mental disabilities, an impaired ability to work, and a compromised quality of life. These problems arise not only from the disease process, but also from social stigma directed toward the affected persons. All of these problems, moreover, have a cumulative, adverse impact at the individual, household, community and national levels. ${ }^{13}$

As there is no such study like treatment seeking behavior in filariasis conducted nationally yet, the finding of the study has been compared with the data of other studies conducted internationally. Regarding the socio-demographic variables in this study, the mean age of the respondents was $41.3 \pm 11.6$ years ranging from 20 to 71 years. From the respondents $59 \%$ were female and $41 \%$ were male, among them $68.5 \%$ were illiterate, about $22.0 \%$ had primary level, about $5.5 \%$ had secondary level and about $4.0 \%$ had higher secondary level of education. Among the respondents 90.5\% were married, about $6.0 \%$ were widow and 3.6 were unmarried. Regarding the occupation $51.5 \%$ were housewife, about $16.8 \%$ were engaged in agricultural farming, about $9.5 \%$ were van driver, about $5.0 \%$ were service holder, about $4.8 \%$ were engaged in business and unemployed were $3.3 \%$. The mean family size of the respondents was $4.91 \pm 1.2$ ranging from 2 to 8. The mean monthly family income was Taka $3792 \pm 1099.3$ ranging from 2000 to 8000. In comparison to this study, a study in Dominican Republic (2006), a Latin American country with filariasis endemic areas found that, $76 \%$ of the $56 \%$ women (all respondents were women) were over 40 years of age, with average age of 50.5 and an age range of $26-80$ years. ${ }^{13}$ About $46 \%$ of respondents were heads of households, and about $71 \%$ were married or in a free union or common low marriage, about $18 \%$ were widowed and about $11 \%$ were single. A study in South India (2003) found that, out of 200 respondents $43.5 \%$ were male and about $56.5 \%$ were female. The mean age of the respondents was 47 years. ${ }^{14}$ About $68.5 \%$ respondents lived in thatched houses, $47.5 \%$ were casual laborers and lived on daily wages or earning.

Regarding the knowledge about the disease in this study, respondents were suffering from $78.5 \%$ respondents mentioned that they did not know. Among the respondents 44.8\% believed that the disease might be caused by supernatural forces, about $23.8 \%$ believed due to familial cause and $31.5 \%$ did not know the cause of the disease. About $93.8 \%$ of respondents did not know the mode of spread of disease. About $85 \%$ of the respondents mentioned that the symptoms of the disease was swelling of the hand and feet, about $67.8 \%$ mentioned swelling of the scrotum, about $5.3 \%$ mentioned non specific symptoms and about $7.3 \%$ had no knowledge on symptoms of the disease. About 94\% did not know the easiest method of prevention of disease. In comparison to this study, respondents in India (1996) showed that $9.3 \%$ of the affected individuals know the cause of filariasis. The cause mentioned by the respondents were following, about 37.8 could not say, about $8.7 \%$ mentioned due to weaving, about $4.7 \%$ mentioned due to drinking water from the ponds/ wells, about $2.3 \%$ mentioned due to accumulation of bad fluid, about $1.2 \%$ mentioned due to heredity and about $33.7 \%$ mentioned due to others. ${ }^{15}$

In a study in Nepal (2003) showed that respondents were asked about their knowledge of LF. ${ }^{16}$ Most of the respondents recognized the signs of LF particularly elephantiasis by their social experience, but 
they had inadequate knowledge of recognition of adenolymphangitis (ADLA), hydrocele, arm swelling and breast swelling as a disease of LF. About $49.3 \%$ said that filariasis was caused by mosquito bite, about 15\% mentioned flies and insects, about $5.6 \%$ blamed poor living status, about $7.5 \%$ believed that evil spirits were responsible and $9.6 \%$ did not know.

Respondents in Malaysia (1986) gave different data of filariasis. Among the knowledgeable respondents $52 \%$ mentioned intestinal worms as agent of filariasis, while $9.2 \%$ mentioned bacteria as an agent. It could be inferred that the majority of the total respondents of the studied area had misconception about the agent of filariasis. ${ }^{17}$ In a study in Haiti (1996) found that only $6 \%$ respondents had knowledge on mode of transmission of filariasis and mentioned that mosquitoes were involved in transmitting the disease. ${ }^{18}$ Another study in Malaysia (1986) found that about $9.2 \%$ of the respondents said that filariasis is transmitted by mosquito bite. ${ }^{17}$

Regarding the psychosocial problems of this study disease $99.8 \%$ respondents faced physical problems, about $22.3 \%$ faced economic problem, about $13.3 \%$ had social problems, about $64 \%$ of the respondents mentioned sexual problems. Study conducted in Haiti (1996) found that, 54\% of the community people mentioned that hydrocele was the main complication followed by elephantiasis $44 \%$. Unexpectedly, they did not mention any other sequel/ complications of filariasis, but in this study $34 \%$ of the respondents mentioned breast and hand swelling. ${ }^{18}$ Study conducted in India (1996) found that lymphoedema patients due to filariasis $15-33 \%$ reported a negative impact on domestic activities, about $65-83 \%$ economic activities, about $67-78 \%$ movement and about $75-85 \%$ sexual activities. ${ }^{2}$ Another study in Haiti (2004) reported that $45 \%$ respondents reported decreased ability to walk, about $65 \%$ reported difficulty in finding appropriate footwear and about 45\% reported sometimes to inability to sold at the market or did household chores. ${ }^{19}$
Regarding treatment seeking behavior of filariasis in this study, about $73.8 \%$ respondents delayed in receiving treatment and about $26.3 \%$ started treatment immediately after appearance of symptoms. Reasons for delayed received treatment $51.5 \%$ respondents mentioned that they did not take seriously and about $48.5 \%$ mentioned that they did not receive advice from any one. Regarding the usual place of treatment in this study, about $89.5 \%$ respondents visited to the homeopath doctor chamber, about $83.5 \%$ visited kabirajbari and about $7.8 \%$ visited qualified doctors chamber (private clinic) and one respondent visited to the government hospital. About $68.3 \%$ respondents purchased medicine timely, about $50.8 \%$ respondents investigation done timely, about $45 \%$ reported that doctor listen the complaints attentively, $44.8 \%$ respondents reported that doctor given treatment attentively, about $42.3 \%$ respondent reported that they received treatment in right time. In a study in Nepal (2003) found that, in most rural areas where people faced many health problems, there was a general tendency to first consult traditional healers, of a total 4488 filarial patients $48 \%$ consulted traditional healers, about $12 \%$ consulted modern medicine practitioners (health assistant, doctor, nurse and private practitioner), among the respondents $32 \%$ used herbal medicine, and $8 \%$ did not seek any treatment. ${ }^{16}$

In a study in India (1996) found that $49-98 \%$ lymphoedema patients sought treatment for ADLA during the previous 6-12 months either by consulting government or private health personnel or self-treatments. ${ }^{20}$ In a study in rural Haiti (1996) found that approximately $50 \%$ of people experience an ADLA episode sought treatment from health clinics, traditional healers or by self-treatments. ${ }^{18} \mathrm{In}$ a study in India (1996) reported that $71 \%$ of the filarial patients preferred treatment from public health facilities, about $26 \%$ from private practitioners, and $3 \%$ underwent self-treatment. ${ }^{20}$ In a study in the Dominican Republic (2006) found that, 94\% of women who were interviewed had sought care for 
chronic lymphoedema, with $96 \%$ were seeking care from traditional providers and about $9.0 \%$ seeking care from trained physicians at some time during the course of their disease. ${ }^{13}$ In a study in Nepal (1996) found that, about $42 \%$ respondents did not visit modern health facilities and instead seek the help traditional healers. ${ }^{20}$ The most recent study in Nepal (2007) documented health seeking behavior in a hill area reported that $69 \%$ of respondents sought health care when an illness occurred and about $26 \%$ of them visited traditional healers exclusively while only $19 \%$ first visited formal health care institution. ${ }^{21}$

Regarding the gender discrimination in treatment of filariasis this study revealed that, the female respondents were received different pattern of treatment than male counterpart. That was in terms of treatment received timely, male were $54.3 \%$ and female were $33.9 \%$; regarding investigation timely done, male $73.2 \%$ and female $61.9 \%$; regarding purchased medicine timely, male were $77.4 \%$ and female $61.9 \%$ and regarding doctor listen the complaints of respondents attentively, male were $55.5 \%$ and female $37.3 \%$. In a study conducted in Africa (2007) found that social discrimination and divorce was high among those women who were having filariasis. ${ }^{22}$ Prostitution was usually the after effect of such neglect. These sets of prostitutes were of the lowest cadre and the high-class prostitutes often refer clients with Sexually Transmitted Disease (STDs) to them.

There may be some limitations in performing this study, which should be taken into consideration. The possible limitations were follows: in the study the sample population was selected from a small area (a ward) of a selected union, which ideally may not be representing the whole population of the district/ country and time allocated for data collection was short due to which sample size was small. A large sample size might help to obtain more valid data for generation.

\section{Conclusions}

Filariasis is still the most important public health parasitic disease in Bangladesh. The consequences of filarial infection are many. A large number of affected persons exhibit physical and mental disabilities, an impaired ability to work, and a compromised quality of life. These problems arise not only from the disease process, but also from social stigma directed toward the affected persons. All of these problems, moreover, have a cumulative, adverse impact at the individual, household, community and national levels. The present study findings support the mentioned situation. Active community participation should be ensured in designing community based education campaigns to get rid of the problems effective. Health workers, NGO workers, teachers, religious leaders, community leaders can play a key role convincing the patients to take modern treatment and enhancing the intake of full course of drugs against filariasis by the patients. Further study is needed using a large scale patients to observe the actual status of treatment seeking behavior of filariasis patients in the community.

\section{Recommendations}

On the basis of present study following recommendations and suggestions are considered: a) active community participation should be ensured in community based education campaigns and design socially acceptable control strategies to increase the possible of acceptance and support of National Filaria Elimination Programme, b) topics on filariasis regarding its sources, mode of transmission, prevention, and elimination may be included in the text book of school level. This will help to create awareness among the students and through them to their family and community, c) distribution of posters, pamphlets, booklets etc and film showing regarding knowledge about disease sources, transmission, prevention and treatment of filariasis in different places of the country to create awareness among the people is necessary and should be improved, d) women need more attention in endemic areas as a group that had been neglected, and e) improve socioeconomic status of women as a gender and social group by small scale business provide by government and NGOs. 


\section{References}

1. Melrose WD. Lymphatic filariasis: a review 1862-2002, Warwick Educational Publishing Inc; Australia, 2004.

2. Ramaiah KD, Vijay KN, Ramu K. Knowledge and beliefs about transmission, prevention and control of lymphatic filariasis in rural areas of South India. Tropical Medicine and International Health 1996;1:433-8.

3. Regional Strategic Plan for Elimination of Lymphatic Filariasis (2004-2007). World Health Organization Regional Office for South-East Asia, New Delhi, August 2004.

4. Lymphatic filariasis- Burden of lymphatic filiariasis in South-East Asia Region, World Health Organization, regional Office for south East Asia, 2008.

5. The Global Elimination of Lymphatic Filariasis Bangladesh 2007, Filariasis Elimination Programme, Directorate General of Health services, Mohakhali, Dhaka-1212, Bangladesh.

6. Anonymous. US AIDS coordinator shuns collaboration on neglected disease. Lancet 2006;368:1547.

7. King C, Dickman K, Tisch D. Reassessment of the cost of chronic helmintic infection: a meta-analysis of disability-related outcomes in endemic schistosomiasis. Lancet 2005;365: 1561-9.

8. Hotez P, Molyneux D, Fenwick A, et al. Incorporating a rapid-impact package for neglected tropical diseases with programs for HIV/AIDS, Tuberculosis and Malaria. PLoS Med. 2006;3:e102

9. World Health Organization Global Programme to Eliminate Lymphatic Filariasis. Weekly Epidemiological Record 2006;22:221-32.

10. World Health Organization. Lymphatic filariasis: progress of disability prevention activities. Wkly Epidemiol Rec 2004;79:417-24.

11. Bockarie M, Molyneux D. The end of lymphatic filariasis? Tropical Diseases. $\mathrm{Br}$ Med J 2009;338:b1686.

12. The Socio-Economic Impact of LF and the Program to Eliminate It: The Global Alliance to Eliminate Lymphatic Filariasis. Geneva: World Health Organization, 1998.
13. Person B, Addiss DG, Bartholomew LK, Meijer C, Pou V, Van den Borne B. Health seeking behaviours and self-care practices of Dominican women with lymphoedema of the leg: implications for lymphoedema management programs. Filaria Journal 2006;5:312-26.

14. Nanda B, Krishnamoorthy K. Treatment seeking behaviour and costs due to acute and chronic forms of lymphatic filariasis in urban areas in south India. Tropical Medicine and International Health 2003;8:55-9.

15. Ramachandran CP. The control of lymphatic filariasis: despair to hope. Filarial Links 1997;2:4-6.

16. Sherchand JB, Obsomer V, Thakur GD, Hommel M. Mapping of Iymphatic filariasis in Nepal. Filaria Journal 2003:2:7.

17. Haliza B, Mohd R. Comparison of knowledge on filariasis and epidemiological factors between infected and uninfected respondents in a Malay community. Southeast Asian Journal of Tropical Medicine and Public Health 1986;17:457-63.

18. Eberhard MJ, Walker EM, Addiss DG, Lammie MJ. A survey of knowledge, attitudes and perceptions (KAPs) of lymphatic filariasis, elephantiasis, and hydrocele among residents in an endemic area of Haiti. American Journal of Tropical Medicine and Hygiene 1996;54:299-303.

19. Wijers DJB. Bancroftian filariasis in Kenya, prevalence survey among adult males in the Coast Province. Annals of Tropical Medicine \& Parasitology 1977;71:313-31.

20. Bandyopadhyay L. Lymphatic filariasis and the women of India. Soc Sci Med 1996;42:1401-10.

21. Addiss DG, Molly A Brady MA. Morbidity management in the Global Programme to Eliminate Lymphatic Filariasis: a review of the scientific literature. Filaria Journal 2007;6:2, http://www.filariajournal.com /content/6/1/2.

22. Okwa O. Tropical Parasitic Disease and Women. Annals of African Medicine 2007;6:157-63.

\section{Suggestion for citation of the above:}

Rahman KMM, Laskar MS, Basu BK, Chowdhury S. Treatment seeking behavior of filariasis patients in a selected endemic area of Bangladesh. Mediscope 2015;2(2):5-15. 